\section{NOTAS SOBRE A ATITUDE MODERNA E 0 CORPO: DISSECAÇÃO, REGISTRO VISUAL, DEMONSTRAÇÃO E EXPERIMENTOS}

\author{
NOTES ON MODERN ATTITUDE AND THE BODY: DISSECTION, VISUAL \\ RECORDS, DEMONSTRATION AND EXPERIMENTS
}

NOTAS SOBRE LA ACTITUD MODERNA Y EL CUERPO: DISECCIÓN,
REGISTRO VISUAL, DEMOSTRACIÓN Y EXPERIMENTOS

João Dias*
Palavras chave: Corpo humano. Técnicas de pesquisa.

Dissecação. Experiências laboratoriais.

Keywords: Human Body. Research techniques. Dissection.

Laboratory

Experiments.

Palabras clave: Cuerpo humano.

Técnicas de investigación.

Disección.

Experimentos de laboratorio.
Resumo: 0 artigo busca evidenciar nuances da atitude moderna sobre corpo humano, tendo como centralidade investigações e sistematizações realizadas por Leonardo da Vinci, Andreas Vesalius, e William Harvey. Ao nos aproximarmos de seus mapas de compreensão do corpo humano, apresentamos alguns tensionamentos com relação aos saberes da tradição, antiga e medieval, bem como algumas de suas proposições, que constituem certa epistémê moderna do corpo humano.

Abstract: The article seeks to show nuances of the modern attitude about the human body, focusing on investigations and systematizations carried out by Leonardo da Vinci, Andreas Vesalius, and William Harvey. As we approach its maps of understanding of the human body, we present some tensions regarding the knowledge of the ancient and medieval tradition as well as some of its propositions, which constitute a certain modern episteme of the human body.

Resumen: Resumen: El artículo trata de mostrar matices de la actitud moderna sobre el cuerpo humano, con foco en investigaciones y sistematizaciones realizadas por Leonardo da Vinci, Andreas Vesalius y William Harvey. Al acercarnos a sus mapas de comprensión del cuerpo humano, presentamos algunas de las tensiones con respecto al conocimiento de la tradición, antigua y medieval, así como algunas de sus propuestas, que constituyen cierta episteme moderna del cuerpo humano.
*Universidade Federal de Alagoas. Maceió, AL, Brasil. E-mail: joao.dias@cedu.ufal.br

Recebido em: 04-04-2017 Aprovado em: 09-01-2018

DOI: http://dx.doi.org/10.22456/1982-8918.72431 (c) (1) (8) Licence 


\section{A NATUREZA DO CORPO HUMANO: DISSECAR PARA CONHECER}

A denominação atitude moderna, aqui utilizada, refere-se a certos deslocamentos significativos do pensamento médico e filosófico, gestados no período moderno, para a compreensão do corpo humano e que serão evidenciados ao longo do artigo. No sentido de contextualizar a apresentação dos argumentos, utilizarei os termos atitude moderna, período moderno e modernidade em alusão à complexidade da conjunção histórica, social, política e filosófica do continente europeu entre os séculos XV e XVIII, sem perder de vista as dificuldades historiográficas, filosóficas e sociológicas que a demarcação temporal desse período envolve. A sistematização da dissecação do corpo humano é um indicador central na configuração da atitude moderna em relação à investigação da materialidade do corpo. A dissecação articula um duplo movimento: (i) particularmente, como técnica de escalpelo, possibilitando uma observação minuciosa por dentro do corpo humano, ou seja, um modo técnico para acessar a arquitetura e o funcionamento da estrutura corporal; (ii) e ainda, mais largamente, como epistémê , ao tornar possível a delimitação e legitimação de campos do conhecimento científico de uma época, inaugurando novos interesses em torno das investigações corpo humano. Essa representação moderna do corpo, sistematizada e divulgada pelo conhecimento da anatomia e da fisiologia, implicou uma nova compreensão da arquitetura do corpo e dos sistemas corporais, influenciando diversos campos do saber, quais sejam médicos, filosóficos e artísticos.

No sentido de retomar uma reflexão pontual sobre o interesse do corpo na modernidade e seus deslocamentos filosóficos e médicos, propomos uma aproximação de elementos que possam nos dizer sobre a atitude moderna ao ocupar-se com o corpo, através de modos de manipulação, investigação e sistematização singulares, que adensaram a atitude de uma época conforme o seguinte imperativo: dissecar para conhecer. A dissecação apresentou-se na modernidade como uma estratégia eficiente para a compreensão do corpo humano, quer dizer, uma "[...] invenção, uma resposta que, num determinado momento, apareceu como adequada ou vantajosa diante da exigência de obter ou de perfazer um novo conhecimento sobre o corpo" (MANDRESSI, 2008, p.411).

A dissecação do corpo humano na modernidade foi um dispositivo, ou ainda, uma técnica de intervenção através da qual se configurou um campo de possibilidades de manipulação e interpretação, apresentando-se naquele momento eficaz e profícua, em termos de sistematização do conhecimento, permitindo apreender em detalhe a organização anatômica e, por vezes, fisiológica do corpo humano.

\section{A MANIPULAÇÃO DO CORPO HUMANO POR LEONARDO DA VINCI}

Em uma primeira retomada, aproximamo-nos dos Cadernos anatômicos do artista renascentista Leonardo da Vinci (1452-1519). Qual o sentido de abeirarmo-nos nessa produção? Pontualmente, ao iniciarmos nossa marcha reflexiva fazendo referência ao artista renascentista, pretendemos ressaltar a gênese de um novo interesse em torno do conhecimento do corpo humano, característico da atmosfera da época, como também suas distensões com relação à tradição antiga e medieval.

Ao manusearmos os Cadernos anatômicos de Leonardo da Vinci podemos perceber prontamente 0 interesse, impulsionado desde o renascimento, na constituição de demandas 
modernas em torno da investigação do corpo. É importante, inicialmente, considerarmos que esse registro faz parte de um projeto mais amplo e ambicioso do artista renascentista ao pretender organizar um Tratado de anatomia, que não chegou a ser concluído em vida. Havia no renascimento um interesse de alguns artistas pelos estudos da anatomia, comumente por uma anatomia superficial, topográfica, para empregar feições "naturais" em suas expressões artísticas. No entanto, o interesse de Leonardo da Vinci pela prática anatômica, apesar de não ser anatomista por formação, superava a questão encerrada na representação do corpo projetada em seus quadros. $O$ artista exerceu, de fato, a técnica da dissecação. Leonardo teve acesso a algumas peças anatômicas e a alguns corpos humanos completos. Dentre eles, destaca-se a dissecação em Florença, entre o inverno de 1507 e 1508, de um homem velho, conhecido como "homem centenário".

Para sistematizar os desenhos de fragmentos do corpo em seus cadernos, Leonardo realizava o procedimento da manipulação direta do cadáver pela dissecação, através da observação sistemática e da manipulação das partes do corpo humano. A repetição da técnica de dissecação, a manipulação e a observação foram procedimentos indispensáveis na constituição do saber anatômico moderno. "Dissecar cadáveres implica o projeto de ir deliberadamente ao encontro das realidades corporais que se pretende discernir pelos sentidos" (MANDRESSI, 2008, p. 418). Nesse quadro geral, a manipulação e a observação compõem a atitude através da qual o dissecador pôde se aproximar diretamente da composição do corpo humano, quer dizer, da natureza que constitui o corpo, tendo como base os sentidos. 0 tato $\mathrm{e}$ a visão precediam o registro dos desenhos e as anotações da prática anatômica repetida por Leonardo da Vinci.

A partir da atitude de observação direta e manipulação do material anatômico humano, destacamos uma primeira variação importante operada pela investigação anatômica renascentista, o que provocou um importante tensionamento com relação ao conhecimento anatômico da tradição antiga e medieval. A referência à tradição médica diz respeito, pontualmente, à influência de um corpus de conhecimento sobre o corpo humano fundamentado na medicina de Hipócrates (460-377a.c.), na filosofia natural de Aristóteles (384-322a.c.), e, com ênfase, nas obras de Galeno (129-217a.c).

Para nos situarmos, grosso modo, nesse cenário, é preciso considerar que os parâmetros da medicina e da filosofia natural se fundamentavam na seguinte tradição: a teoria humoral do corpus hipocrático (HIPPOCRATES, 1999); a centralidade do coração como sede do movimento corporal de acordo com princípios aristotélicos (ARISTOTE, 1964); e a explicação da circulação do sangue tendo como referência a autoridade da medicina de Galeno (GALIEN, 1994). É preciso observar, ainda, que a medicina galênica, além de incorporar alguns elementos hipocráticos e aristotélicos em sua formulação, como a teoria humoral e a compreensão aristotélica da disposição dos órgãos a partir da noção de causas finais, avançou na elaboração e sistematização de uma teoria médico-filosófica que influenciou e se fez presente durante o medievo.

De Aristóteles, Leonardo inicialmente aproximou-se de sua explicação vascular que considera o coração como fonte do sistema circulatório, e, posteriormente afastouse, acercando-se de uma variação da teoria de Galeno ao considerar o fluxo e o refluxo do sangue para explicar a circulação. Sob a influência da medicina de Galeno, Leonardo considerou em suas investigações o fígado composto por cinco lobos. Ao mesmo tempo, 
apresentou distanciamentos da filosofia galênica, para citar um exemplo, ao compreender 0 fluxo dos alimentos pelo tubo digestivo relacionado a uma estrutura composta pela respiração, contrações diafragmáticas e sistema muscular abdominal (O'MALLEY; SAUNDERS, 2012b; SINGER, 1996).

A dissecação até então realizada pela medicina tradicional foi eminentemente marcada pelo escalpelo e vivissecção de animais, posteriormente, transferidas para o corpo humano. Por esse método a estrutura analisada dos animais sofria uma adaptação para as dimensões do corpo humano, resultando, por exemplo, no aumento das proporções das partes analisadas. A compreensão da anatomia do corpo humano passava por certa modelagem da dissecação procedida em animais. Leonardo também realizou dissecações de animais, no entanto, sua compreensão diferenciada do corpo humano assentou-se em sua dissecação direta, bem como na sistematização de suas observações em registros visuais.

O desenho foi utilizado por Leonardo da Vinci como um método para o registro visual da estrutura do corpo humano, dando novos contornos ao registro da medicina, até então baseada na prevalência da descrição textual.O artista renascentista, "[...] buscando emancipar-se de um aristotelismo medieval desgastado, caminhava através de um galenismo deturpado e tentava conquistar uma posição de relativa independência" (O'MALLEY; SAUNDERS, 2012b, p. 25).

A investigação leonardiana em torno da anatomia do corpo humano não influenciou diretamente a produção do conhecimento anatômico e as rupturas provocadas a partir dos séculos XVI e XVII, o que inclui o período de produção do pensamento de Andreas Vesalius e William Harvey, pois os estudos anatômicos de Leonardo foram publicados somente no final do século XIX. No entanto, seu interesse pela investigação da materialidade corporal e a utilização de novos modos de investigação apontam para uma nova atitude com relação à compreensão do corpo humano, que passa, necessariamente, pela sistematização da técnica de dissecação, pela observação direta da anatomia do corpo humano e pelo registro visual.

A dissecação do material anatômico humano foi, desde o renascimento, uma atitude voltada preponderantemente para a investigação no que diz respeito ao corpo, tanto médica, filosófica, quanto artística, compondo uma nova paisagem para a compreensão do homem a partir da modernidade. Trata-se, desde então, de uma técnica e de uma epistémê que pelo corte invade o interior do corpo humano, observando-o sistematicamente, manipulando-o diretamente, registrando-o detalhadamente, no sentido de buscar a compreensão de certa natureza humana.

\section{PROJETO ANATÔMICO DE ANDREAS VESALIUS}

$\mathrm{Na}$ busca por retomar elementos em torno da atitude moderna em torno do corpo, direcionaremos nossos apontamentos para um segundo movimento. Trata-se da reorganização do conhecimento anatômico promovido pelo médico Andreas Vesalius e amplamente divulgado, principalmente entre os séculos XVI e XVII, pela sistematização e publicação em 1543 de sua obra De Humani Corporis Fabrica. Por qual motivo nos aproximamos de Andreas Vesalius?

O médico e professor Andreas Vesalius (1514-1564) é considerado por muitos comentadores da história da medicina como um dos responsáveis por inaugurar a anatomia moderna, distinção atribuída, principalmente, pela publicação de sua obra De Humani 
'Corporis Fabrica. É o primeiro atlas de anatomia detalhadamente ilustrado com imagens e tendo como referência o estudo, a observação e a dissecação direta do corpo humano , considerando que até então os manuais de medicina das escolas médicas enfatizavam a erudição dos textos da tradição. O projeto vesaliano, amplamente divulgado pela circulação de sua obra, imprimiu importantes deslocamentos na forma de organização e produção do conhecimento da medicina, tendo como princípio a manipulação e a observação direta das partes anatômicas do corpo humano.

Do ponto de vista da organização e difusão do conhecimento médico, o princípio da manipulação e observação direta de cadáveres humanos, realizado por Vesalius, implicou uma importante mudança de caráter pedagógico. Tradicionalmente, a anatomia era ensinada nas escolas de medicina centrada em uma estrutura que promovia, por um lado, a exaltação do texto escrito referente à tradição, e, por outro lado, o distanciamento do corpo a ser examinado. Essa estrutura articulava três figuras, representadas, hierarquicamente pelo Lector, o Ostensor e o Sector'. O Lector, identificado como o professor de anatomia, era responsável pela leitura, geralmente em um púlpito, de um texto clássico de medicina. Cabia ao Ostensora tradução do texto para a língua vernacular do público que acompanhava a aula, a indicação do local destacado pelo texto na peça anatômica e de como proceder ao corte, que deveria ser realizado, por sua vez, pelo Sector, um assistente, cirurgião ou barbeiro, responsável por manipular o cadáver e realizar a dissecação.

O professor de anatomia encontrava-se próximo do texto e distante do corpo a ser dissecado. 0 ensino era baseado na instrução e autoridade dos textos clássicos e não na investigação e manipulação direta das peças anatômicas. O conhecimento estava atrelado às obras da tradição, aglutinada pelo corpus hipocrático, pela filosofia aristotélica e pelos textos galênicos. Em síntese, o anatomista não manuseava o cadáver, nem mesmo dominava os procedimentos técnicos para a realização do escalpelo.

No entanto, Andreas Vesalius, como registrado em sua obra, reorganizou o modo de expor e ensinar o conhecimento da anatomia, comumente enfatizada na erudição dos textos da tradição e no distanciamento do cadáver. Tal mudança procedeu pela observação, manipulação e dissecação direta do corpo humano. 0 médico belga também produziu suas próprias pranchas anatômicas, na forma de imagens, a partir de suas investigações, reorganizando elementos do conhecimento da medicina, a partir de sua maneira inovadora de sistematizar, expor e tornar público o conhecimento anatômico. Como era comum em suas aulas, ou em suas demonstrações públicas de dissecação, Vesalius desce do púlpito para se localizar no centro do acontecimento, 0 anatomista manipula o cadáver de uma mulher e irrompe definitivamente com o modelo tradicional de ensino da anatomia, ao proceder, ele mesmo o escalpelo, diretamente no corpo a ser investigado.

Ao sistematizar seu atlas anatômico, Vesalius empenhou-se em investigar a constituição da estrutura da materialidade humana, através da seguinte pergunta: qual a natureza do corpo humano? Esse conhecimento seria alcançado por um método específico de exploração das camadas do corpo, em outras palavras, pelo uso da técnica da dissecação, da observação direta e do registro visual, horizonte presente na investigação leonardiana. No tratamento e apresentação da natureza do corpo, Vesalius organizou sua obra esquematicamente em sete

1 Havia uma pequena variação dessa estrutura quanto à presença ou não do Ostensor. Em sua ausência, a tradução e comentários eram realizados pelo próprio professor de anatomia (KICKHÖFEL, 2003; TERRA, 2007; REBOLLO, 2013). 
livros, ou sete camadas, respectivamente: os ossos, os músculos, o sistema circulatório, o sistema nervoso, o abdômen, o tórax e o cérebro. Constituiu o percurso da dissecação em consonância com a composição do corpo, notadamente, de sua estrutura interna para o seu arranjo mais exterior. O ponto de partida do atlas vesaliano são os ossos e os músculos, enfatizando, inicialmente, a sustentação do corpo humano para, posteriormente, descrever os grandes sistemas até chegar ao cérebro.

Vesalius organizou a sequência dos livros em De Humani Corporis Fabrica com referência, em seu entendimento, na própria ordenação da natureza e na forma de compreender a arquitetura anatômica do corpo humano. Iniciar a apresentação do corpo pelos ossos diz respeito também ao reconhecimento da composição inicial do corpo pela natureza a partir da estrutura óssea. Pois os ossos dão o fundamento e a sustentação à estrutura da fábrica do corpo humano. "Começar pelos ossos é também o que recomenda Galeno no De anatomicisadministrationibus ${ }^{2}$, porque dos ossos dependem, diz ele, a forma e o apoio do corpo, como os postes para as tendas ou as paredes para as casas" (MANDRESSI, 2008, p. 431).

Considerando que Galeno não realizou a dissecação do corpo humano, Vesalius, ao manipular e observar diretamente cadáveres humanos, pôde identificar e demonstrar confusões e equívocos do entendimento galênico a respeito da estrutura do corpo humano. Como, por exemplo, ao investigar a estrutura muscular. Vesalius demonstrou a distinção entre nervos e tendões, diferentemente dos ensinamentos galênicos, ao identificá-los, simplesmente, como nervos.

É importante ter em vista a tensão epistemológica provocada por De HumaniCorporis Fabrica, o que levou certos comentadores a identificarem, com a publicação dessa obra, o surgimento da ciência moderna ${ }^{3}$. O critério por eles estipulado orbita em torno da observação direta dos fenômenos como marco na configuração da ciência em sua compreensão moderna. Discorrendo sobre a obra vesaliana em questão, trata-se da observação direta do cadáver humano viabilizada pelos procedimentos do médico belga. 0 projeto anatômico de Andreas Vesalius pôde ser assim compreendido como um modo de racionalização do corpo humano, fundamentado na dissecação, que, por sua vez, permitiria o acesso à natureza do corpo. Nesse contexto, destacamos a seguir duas possibilidades de entendimento da configuração da ciência, em termos modernos, no diálogo com o projeto vesaliano.

Em um sentido estrito e pontual, a configuração da ciência moderna tem sua regulação mediada pela preparação da experiência. Ressaltamos que não se trata da experiência cotidiana, mas da experiência enquanto experimentum. Em outras palavras, diz respeito à realização de uma experiência que visa investigar a natureza, previamente concebida, preparada e articulada com as teorias e fundamentos da física e da geometria. Ultrapassase,nesse sentido, uma simples observação direta dos fenômenos. 0 experimentum não se encerra na percepção experimental do fenômeno em questão. Nesses termos, a explicação do mundo passa, segundo Koyré (2011), a ser compreendida em conformidade com o modelo galileano, quer dizer, de acordo com a geometria e a física. Esse novo método pretende tanto a realização de experimento como a sua quantificação. A verdade da explicação dos fenômenos

2 "Galeno utiliza o termo administrationibus para descrever os procedimentos anatômicos ou a preparação feita para experimentos de vivissecção animal. Vesálio[...] para denominar o próprio procedimento de vivissecção animal” (REBOLLO, 2013, p. 134). 
da natureza, por exemplo, tem nesse modelo a afirmação das leis da física e da linguagem da matemática.

Ainda em regime estrito de compreensão da configuração da ciência moderna, a proposta vesaliana poderia não ser apresentada de maneira a cumprir tais exigências. A ênfase da experiência anatômica em Vesalius situa-se na descrição do corpo humano e não em sua submissão à linguagem física e matemática na explicação da natureza do corpo. Em síntese, nessa perspectiva, o destaque do corpo humano a partir listagem de uma série de elementos qualitativos, como, por exemplo, na descrição das imagens, não se acomodaria na racionalidade da ciência moderna (KIKCHÖFEL, 2003).

No entanto, em sentido extenso e mais abrangente, assinalamos que, do ponto de vista da configuração de uma epistémê, é preciso considerar, além da observação direta, os procedimentos adotados por Andreas Vesalius na realização de um estudo analítico de seu objeto. Senão vejamos, a anatomia vesaliana configurou-se por meio da investigação racional e de pesquisas empíricas; na preparação do corpo humano e nas estratégias para dissecá-lo; no cuidado e na preparação no uso de técnicas e tecnologias para proceder a dissecação através, por exemplo, da preparação de uma série de instrumentos para efetivar no corpo humano o escalpelo, a busca da verdade sobre a natureza do corpo; na atitude crítica, inovadora e questionadora de certos conhecimentos da tradição, ao refutar, por exemplo, algumas assertivas de Galeno; na demonstração em público e na repetição de seus procedimentos para pautar e fundamentar suas explicações a respeito da organização e do funcionamento do corpo humano; no recurso imagético como uma maneira de registrar, descrever a experiência e demonstrar 0 conhecimento sistematizado. Considerando a história da constituição da racionalidade médica, Vesalius contribuiu, decisivamente, para a organização da epistémê do corpo humano.

\section{A CIRCULAÇÃO DO SANGUE E A QUANTIFICAÇÃO DO CORPO EM WILIAM HARVEY}

Nosso terceiro movimento argumentativo, para finalizar nossa marcha sobre a delimitação de certa atmosfera em torno da atitude moderna diante do corpo humano, remetenos às pesquisas realizadas pelo médico inglês William Harvey (1578-1657). É decisivo considerar que o debate sobre o funcionamento do coração e a circulação sanguínea ocupou grande interesse por parte dos médicos, os quais geralmente seguiam a tradição compreendida por Aristóteles e Galeno. A obra de Harvey, Estudo anatômico sobre o movimento do coração e do sangue nos animais (1628), passou a circular na França em 1629 e teve uma importante repercussão no meio médico e filosófico, mesmo que sua formulação fosse, por vezes, contestada em favor da força da tradição.

William Harvey também provocou deslocamentos significativos na compreensão do corpo humano em sua época e, em particular, quanto à explicação da circulação sanguínea, acarretando, portanto, uma revisão de elementos das teorias aristotélicas e galênicas quanto ao movimento do sangue no corpo. Como era compreendida a função do sangue e a dinâmica do funcionamento cardiovascular pela filosofia natural da tradição?

O fluxo e o refluxo de sangue em Aristóteles tinham suas referências no movimento do coração, no movimento pulmonar e na passagem do sangue pelos vasos. O coração para Aristóteles era o órgão responsável pela vida dos animais sanguíneos. Guarnecido pelo princípio do movimento, o coração seria a fonte de calor inato e de sangue para o corpo. Para 
o filósofo grego, o coração possuía três cavidades e era o princípio, quer dizer, arché, no qual se originariam todos os vasos que iriam nutrir o corpo com sangue e calor. Nesse sistema, os pulmões, responsáveis pela respiração, receberiam uma grande quantidade de sangue do coração por um vaso e, por sua vez, teriam como função arrefecer o corpo.

$\mathrm{Na}$ anatomia e na fisiologia aristotélicas, os pulmões e o coração se comunicariam por uma perfuração na traqueia, "vasos especiais", que se prolongariam entre os dois órgãos. Por essa ligação, o coração receberia o ar (pneuma) dos pulmões, lançado, por sua vez, ao corpo pela circulação sanguínea nos vasos (ARISTOTE, 1964; REBOLLO, 2013). Nessa perspectiva, o sangue, principal parte homeômera do corpo, seria produzido pela cocção de alimentos e sua função dizia respeito à nutrição e à constituição corporal. Formado no coração, o sangue manteria seu fluxo para todo o corpo através dos vasos, carregando nutrientes misturados com ar, proveniente da comunicação entre os pulmões e o coração. 0 ar, presente no sangue, teria como função resfriar o corpo. Ao partir do coração para o corpo, o sangue não retornaria ao coração, pois, na perspectiva aristotélica, o sangue seria responsável por constituir, em um movimento centrífugo, a estrutura corporal.

Já em Galeno, a fisiologia corporal tem como fundamento uma série de faculdades naturais que realizam funções específicas no corpo, de nutrição, de transformação dos alimentos em sangue, do sangue em tecido corporal, coesão das substâncias, crescimento do organismo, entre outras funções. As faculdades naturais estariam divididas da seguinte maneira: nutritiva, atrativa, sanguificativa, neurificativa, ossificativa, cartilaginativa, aglutinante, assimiladora e aumentativa. Ainda em sua fisiologia encontramos a produção de três gêneros de espíritos que circulam no corpo pelo movimento de irrigação sanguínea, quais sejam, os espíritos naturais, produzidos no fígado e encarregados pela nutrição e crescimento; os espíritos vitais, gerados no lado esquerdo do coração e incumbidos de resfriar e manter vivo o organismo; e os espíritos animais ou psíquicos, formados no cérebro e relacionados ao movimento corporal, às sensações e ao pensamento (GALIEN, 1994; DONATELLI, 2000; REBOLLO, 2013).

Fonte e sede do fogo cardíaco, paraGaleno o coração poderia ser dividido em dois lados, direito e esquerdo, e em três cavidades, aurícula direita, aurícula esquerda e ventrículo esquerdo. 0 lado direito do sistema cardíaco, rico em espíritos naturais, estaria articulado com o fígado e formaria o sistema venoso ou sanguíneo, no qual o fígado teria a função de produzir o sangue. $O$ lado esquerdo formaria um órgão com o pulmão, constituindo o sistema arterial ou espirituoso, e a função desse sistema diria respeito à gênese e à circulação pelo corpo dos espíritos vitais. Do lado direito ao lado esquerdo do coração, Galeno admitia a passagem de sangue, ou anastomoses, tanto pelo septo cardíaco, como também entre as veias e as artérias. O sangue, ao irrigar o corpo, levaria respectivamente, espíritos nutritivos, vitais e animais, absorvidos pelas diversas partes do corpo. Sua formação seria, novamente, retomada pelo fígado e dependente da ingestão de alimentos. Além de apontar a diferença entre veias e artérias, Galeno identificou a presença de quatro válvulas no sistema cardíaco, que impediriam o retorno na passagem do sangue: duas sigmóideas, a válvula tricúspide e a bicúspide. Nesse sistema, a pulsação das artérias seria consequência da diástole cardíaca (GALIEN, 1994; REBOLLO, 2013).

Quais as rupturas e continuidades dessas compreensões aristotélicas e galênicas na investigação herveyana? Em Harvey, o coração é o fundamento da vida dos animais, "[...] o soberano de todos os seus órgãos, o sol do microcosmo, a fonte a partir da qual todo 0 
crescimento depende, todo o poder e toda a força emanam" (HARVEY, 2013, p.159). Sua prática anatômica realizou-se na dissecação de corpos humanos e em mais de uma centena de animais, incluindo a vivissecção, para tratar, com ênfase, do movimento circular sanguíneo no corpo. Quer dizer, Harvey compreendia a circulação sanguínea de modo centrípeto e não centrífugo do sangue, como era admitido pelos conhecimentos da tradição, como, por exemplo, na obra galênica.

Nessa relação com o conhecimento da tradição, o movimento nem sempre é de ruptura. Por exemplo, nas investigações e aulas públicas, realizadas reiteradas vezes, o médico inglês buscava compreender e demonstrar as funções dos órgãos e das partes do corpo, a partir da finalidade de sua presença no organismo, quer dizer, dada sua influência aristotélica, precisar a causa final ${ }^{4}$. No entanto, como muitas de suas investigações eram realizadas durante suas aulas públicas, permitindo a demonstração ocular no momento da dissecação, evidenciavamse distensões com relação ao conhecimento da tradição impresso nos livros.

Para Harvey, a prática da dissecação deveria identificar o lugar, a figura, a quantidade, o movimento ou atividade e a divisão das partes dos órgãos ou partes do corpo. Em seus relatos anatômicos, a repetição da dissecação configurava-se como um momento de revisão de suas anotações, realizadas anteriormente, como também cumpria a função metódica de possibilitar o teste, a evidência e a prova do conhecimento em questão, por exemplo, ao manusear novamente o órgão ou a parte do corpo para compreendê-lo. Em Harvey, os experimentos eram situações antecipadamente preparadas para resolver determinados problemas ou questões e cumpriam a atribuição de mediar a descoberta de certa função de um órgão ou de uma parte do corpo, bem como a possibilidade de executar tal descoberta publicamente através da demonstração (REBOLLO, 2013).

Se em Vesalius a linguagem matemática não se fez presente, Harvey se valerá dela para fundamentar suas investigações. Os argumentos quantitativos, fundamentados em cálculos matemáticos, estão presentes em várias passagens de seu Estudo anatômico sobre o movimento do coração e do sangue nos animais. Como exemplo desse procedimento quantificador, ao tratar da pequena e a grande circulação, pulmonar e sistêmica, do regresso sanguíneo para o coração e de sua pulsação para o corpo, o médico inglês argumenta em medidas quantitativas o volume de sangue em circulação para demonstrar seu movimento circular. Contestava, assim, a tese da tradição, inclusive ao demonstrar que a quantidade de sangue não está relacionada com a ingestão de alimentos.

Ainda referente ao critério de análise apoiado no cálculo, bem como no que diz respeito às descontinuidades com relação ao conhecimento da tradição da medicina e da filosofia natural, destacamos os argumentos acentuados por Harvey sobre o movimento contínuo e circular do sangue no coração. $O$ médico inglês ratifica o coração como origem da pulsação sanguínea; e das artérias, jamais as veias, como receptoras do sangue do ventrículo cardíaco esquerdo para sua circulação no corpo. Reitera que a quantidade de sangue presente no corpo seria maior do que a provida pela ingestão de alimentos. Aborda o retorno do sangue ao coração pelas veias, como também a presença e a função de válvulas membranosas nas veias e sua inexistência nas artérias. Para tanto realizou experimentos oculares amarrando, com uma ligadura, o braço de um homem vivo, para demonstrar a possibilidade de calcular a quantidade de sangue que

\footnotetext{
4 Na perspectiva aristotélica, a natureza compreende os princípios de movimento, forma e finalidade. Ao movimento vinculam-se noções como mudança, crescimento e desenvolvimento das coisas; a forma tem sua referência na identidade dos objetos, particularizando um dos demais; e a finalidade confere um telos às coisas.
} 
circula rapidamente na veia, a partir de sua observação direta. "É, pois, necessário concluir que o sangue nos animais se agita com um movimento circular e perpétuo e que a única causa desse movimento está no coração, que exerce essa ação ou função por meio da compressão ou pulsação" (HARVEY, 2013, p. 247).

Harvey apontava para a importância do uso da experiência sensível, como, por exemplo, a observação ocular: "Observei, com a ajuda de uma lente de aumento, o coração batendo e o exibi a todos, para que também o vissem" (HARVEY, 2013, p. 193). O uso dos sentidos vinculavam-se, na sistematização do conhecimento pelo médico inglês, como um primeiro nível de descoberta e confirmação de que algo existe, quod siti: "[se] alguém colocar firmemente o dedo sobre o pedaço da artéria subjacente à atadura, perceberá que ela volta a pulsar e sentirá o sangue correr sob seu dedo" (HARVEY, 2013, p. 229). Este procedimento, ulitizado como prova, poderia ser repetido e demonstrado publicamente. Na configuração de uma epistémê harveyana, destacamos a relevância em valer-se de dados quantitativos, matemáticos, na demostração de suas descobertas (REBOLLO, 2013).

\section{CONSIDERAÇÕES FINAIS SOBRE A ATITUDE MODERNA E O CORPO}

A atitude moderna na investigação do corpo humano influenciou decisivamente o campo médico e a reflexão filosófica em torno do corpo que se constituiram ao longo da modernidade.Compreendemos que a atitude moderna sobre o corpo ganhou ênfase com 0 avanço da técnica de dissecação, o registro visual, as demonstrações e os experimentos, possibilitando a configuração de uma epistémê moderna em torno do corpo humano. Tratouse de um movimento argumentativo que valeu-se dos estudos anatômicos de Leonardo da Vinci, movendo-se na sistematização do mapeamento do corpo através do atlas de anatomia de Andreas Vesalius e sobressaindo-se no uso da linguagem matemática e nos experimentos de William Harvey. A precisão do corte e a técnica de escalpelo nortearam, grosso modo, um duplo sentido, quais seja, possibilitar certo acesso à arquitetura da materialidade corporal e a demarcação de deslocamentos epistemológicos na medicina e na filosofia natural.

De maneira geral, as três referências aqui destacadas apontam para o interesse cada vez mais contundente na modernidade em conhecer e investigar o corpo humano, ao observálo de maneira meticulosa e manuseá-lo em seus fragmentos e articulações, peças anatômicas e processos fisiológicos que fundamentaram métodos e intervenções para a compreensão da arquitetura do corpo humano. Em um movimento de síntese, a partir de nossa argumentação, destacamos os seguintes elementos em torno da atitude moderna diante do corpo: (i) a sistematização do corte e a repetição da dissecação como um modo, por excelência, de investigação do corpo humano; (ii) o registro imagético do corpo humano como um recurso pedagógico para o conhecimento da materialidade corporal; (iii) as demonstrações e os experimentos fundamentados em termos matemáticos como indicadores para a configuração de saberes sobre o corpo; (iv) a problematização e a reformulação de conhecimentos médicos e filosóficos configurando novos discursos na compreensão da estrutura anatômica e fisiológica, até então com fortes vínculos aos diagnósticos da escola hipocrática, às explicações aristotélicas e aos postulados galênicos. Esses movimentos investigativos terão ressonância e serão ampliados e resignificados, ao longo da história do corpo no ocidente. 


\section{REFERÊNCIAS}

ARISTOTE. Histoiredesanimaux. Traduction: Pierre Louis.Paris: Belles Lettres, 1964.

DONATELLI, Marisa Carneiro de Oliveira Franco. Da máquina corpórea ao corpo sensível: a medicina em Descartes. 2000. 179 f. Tese (Doutorado) - Programa de Pós-graduação em Filosofia da Universidade de São Paulo, São Paulo, 2000.

FOUCAULT, Michel. As palavras e as coisas. 9.ed. São Paulo: Martins Fontes, 2007.

GALIEN. Oeuvres médicales choisis I: de l'utilité des parties du corps human. Paris: Gallimard, 1994.

HARVEY, William. Estudo anatômico sobre o movimento do coração e do sangue nos animais. In: REBOLLO, Regina André. William Harvey e a descoberta da circulação do sangue. São Paulo: Editora Unesp, 2013.p. 157-271.

HIPPOCRATES. L'art de la médicine. Paris: GF-Flammarion, 1999.

KICKHÖFEL, Eduardo Henrique Peiruque. A lição de anatomia de Andreas Vesalius e a ciência moderna. Scientiae Studia, v. 1, n. 3, p. 389-404, jul./set. 2003.

KICKHÖFEL, Eduardo Henrique Peiruque. A ciência visual de Leonardo da Vinci: notas para uma interpretação de seus estudos anatômicos. Scientiae Studia,v. 9, n. 2, p. 319-355, abr./jun. 2011.

KOYRÉ, Alexandre. Estudos da história do pensamento científico. 3. ed. Rio de Janeiro: Forense, 2011.

MANDRESSI, Rafael. Dissecações e anatomia. In: Corbin, Alain; COURTINE, Jean-Jacques; VIGARELLO, Georges. História do corpo 1:da Renascença às Luzes. 2. ed. Petrópolis: Vozes, 2008.v. 1, cap. 6, p. 411-440.

O'MALLEY, Charles D. ; SAUNDERS, John Bertrand. Leonardo da Vinci e seus Estudos Anatômicos. In: DA VINCI, Leonardo. Os Cadernos anatômicos de Leonardo da Vinci. Tradução: Pedro Carlos Piatino Lemos e Maria Cristina Vilhena Carnevale.Cotia, São Paulo: Ateliê; Campinas: Editora da Unicamp, 2012a.p. 15-24.

O'MALLEY, Charles D. ; SAUNDERS, John Bertrand. As conquistas anatômicas de Leonardo da Vinci. In: DA VINCI, Leonardo. Os Cadernos anatômicos de Leonardo da Vinci. Tradução: Pedro Carlos Piatino Lemos e Maria Cristina Vilhena Carnevale.Cotia, São Paulo: Ateliê Editorial; Campinas: Editora da Unicamp, 2012b. p. 25-30.

REBOLLO, Regina André. William Harvey e a descoberta da circulação do sangue. São Paulo: Editora Unesp, 2013.

SAUNDERS, John Bertrand; O'MALLEY, Charles D. Andreas Vesalius de Bruxelas (1514-1564): Esboço biográfico. In: VESALIUS, Andreas. De HumaniCorporis Fabrica. Epitome. Tabulae Sex. São Paulo: Ateliê Editorial; Imprensa Oficial do Estado; Campinas: Editora da Unicamp, 2002.p. $15-42$.

SINGER, Charles. Uma breve história da anatomia e da fisiologia desde os gregos até Harvey. Campinas: Editora da Unicamp, 1996.

TERRA, Vinícius Demarchi Silva. Memórias anatômicas. 2007. 167 f. Tese (Doutorado) - Programa de Pós-graduação em Educação da Universidade Estadual de Campinas, São Paulo, 2007. 
VESALIUS, Andreas. De HumaniCorporis Fabrica. Epitome. Tabulae Sex. São Paulo: Ateliê Editorial; Imprensa Oficial do Estado; Campinas: Editora da Unicamp, 2002. 